\title{
ROLAND BARTHES. A DOR DO LUTO
}

Rodrigo Fontanari ${ }^{1}$

É publicado pela editora parisiense Seuil mais um manuscrito de Barthes, intitulado de Journal de deuil (Diário de luto). Roland Barthes (19151980) foi escritor, sociólogo, crítico literário, semiólogo e filósofo francês; influenciado pelos trabalhos do linguista Ferdinand de Saussure, pertenceu à escola estruturalista. Esse diário é fruto do trabalho de Nathalie Léger, diretora adjunta do Institut Mémoires de L'édition Contemporaine (Imec), que também organizou, anotou e apresentou os dois últimos cursos de Roland Barthes no Collège de France, A preparação do romance $I$ e $I I$. Desta vez, a incursão de Nathalie Léger se deu em torno de cerca de 330 fichas manuscritas por Barthes, nem todas datadas, embora a maioria o seja. São breves pinceladas de uma escritura marcada profundamente pela dor do luto. Esse livro contempla dois anos da vida de Barthes, entre 26 de outubro de 1977 e 21 de junho de 1979. São notações quase diárias, a partir da morte da mãe do autor, em 25 de outubro de 1977. Esse volume póstumo encontra-se atualmente traduzido por Álvaro Manuel Machado para editora portuguesa Edições 70.

Há ainda um hiato em torno desse diário, se é que podemos realmente considerá-lo "uma obra póstuma" de Roland Barthes, pois o que nos vem ao espírito a partir da leitura dessas fichas é que ali expressa-se um Barthes final que se interroga sobre a possibilidade de escrever o presente e, sobretudo, escrever a vida em forma de escritura breve. Em suas palavras: "escrever só é plenamente escrever quando há renúncia à metalinguagem; não se pode, portanto, dizer o Querer-Escrever senão na língua do Escrever (...)" (2005, p. 17).

O modelo escritural assumido por Barthes nesses registros, evidente para quem tem familiaridade com sua obra, é a poética mínima do haikai. Trata-se de pequenas cenas oferecidas a um "eu", menos contemplativo que observador, que se detém a registrar a passagem das horas, dos dias e das estações, já que o imperativo do haikai é o tempo que faz: o calor do verão, o vento frio do outono, a primeira neve do ano. Tal era a obsessão do autor por essa forma de poesia, que lhe dedica parte do tempo de suas conferências no Collège de France, durante o curso A preparação do romance I [1978-79]. Entretanto, anteriormente, em $O$ império dos signos [1970], há uma subdivisão inteiramente dedicada às

1 Doutorando pelo Programa de Pós-graduação em Comunicação e Semiótica da Pontifícia Universidade Católica de São Paulo. E-mail: Rodrigo-fontanari@hotmail.com 
diferenças entre a arte oriental e a ocidental, intitulada de "Incidente" (no singular) em que ele revela ao leitor ocidental essa forma breve e pontual de escritura oriental. A obsessão pelo haikai nasce do seu fascínio quanto à forma concisa que não busca reduzir um evento complexo a uma forma breve, mas achar uma forma justa, que faz "agir sobre a própria raiz do sentido, para fazer com que esse sentido não se difunda, não se interiorize, não se torne implícito, não se solte, não divague no infinito das metáforas, nas esferas dos símbolos." (BARTHES, 2007, p. 98).

Esses pequenos e pontuais registros de luto que compõem esse livro não são senão a matéria mesma do haikai. São textos curtíssimos e secos, em que nada vibra para além da referência ao tempo: mais existem do que fazem sentido; pela sua própria matéria-prima, registro pontual e claro do que aconteceu. Se Barthes os aprecia é justamente porque sinalizam o mesmo tipo de notação do presente que ele almejaria para o seu romance, se um dia pudesse escrever um. De maneira poética, Barthes apresenta seu desejo de escritura:

(...) a convicção de que não tenho Memória (...) me proíbe o romance anamnésico (...) minha fraqueza de memória é outra: é uma verdadeira fraqueza (...) lembro-me muito mal das datas de minha vida (...). Tenho, sem dúvida, algumas lembranças repentinas, flashs de memórias, mas eles não proliferam, não se associam ("torrenciais") (...) São imediatamente esgotados na forma breve (...), daí a impressão de "romanesco" que se pode ter, mas também, precisamente, o que separa do Romance. (2004, p. 32-33).

O texto não surpreenderá os conhecedores de Roland Barthes. Ele segue e parece arrematar o ciclo dos diários, iniciado com a publicação do livro Incidentes - organizado por François Wahl e lançado em 1987, pela mesma editora. Incidentes cobre dois lapsos de tempo: um período mais longo, que vai de 1968 a 1969, em que Barthes viveu no Marrocos, e o curto período de 24 de agosto a 17 de setembro de 1979, cujo interesse está em recolher notas feitas às vésperas de sua morte em Paris.

Como fica sabendo o leitor, este diário de luto propõe uma última surpresa: uma profunda e dolorosa parcela da vida íntima transtornada, na época, por uma perda recente: a da mãe, Henriette Binger, que nasceu em 1893 e casou-se com Louis Barthes aos vinte anos de idade, foi uma jovem mãe aos vinte e dois, no ano seguinte tornou-se viúva de guerra e, em 25 de outubro de 1977, aos oitenta e quatro anos de idade, faleceu em Paris (LÉGER, 2009, p. 8-9). O acontecimento foi para Barthes um grande golpe. Desde então, ela se torna um de seus temas mais recorrentes, surgindo até mesmo em meio aos cursos no Collège de France. Como mostra este trecho do belo livro O neutro: "Entre o momento em que decidi o objeto deste curso (...) e o momento em que precisei prepará-lo, 
ocorreu em minha vida (...) um acontecimento grave, um luto: o indivíduo que vai falar do Neutro já não é o mesmo que decidiu falar dele (...).” (2003, p. 32).

Pela ausência do pai morto em guerra, a mãe tornara-se a figura central na vida do semiólogo. Como ele mesmo sublinha na última obra publicada em vida, A câmara clara [1979], “(...) o que perdi não é uma Figura (a Mãe), mas um ser; e não um ser, mas uma qualidade (uma alma): não a indispensável, mas a insubstituível." (2004, p. 113). Poderíamos dizer que o Journal de deuil não é senão um testemunho febril da dor aguda - e, para falar como Barthes, "pungente" (de punctum) - da perda da mãe. A sequência progressiva dos registros da dor do luto nos revela que o tempo não foi capaz de apagá-la, que simplesmente eliminou o caráter dramático do trauma, mas não os sentimentos de abandono, solidão e tristeza anotados no diário. Assim, temos, por exemplo, estas notas na ficha de 11 de junho de 1978: "Comecei de manhã a olhar suas fotos [de sua mãe] / Um luto atroz recomeçou (mas não tinha cessado)" (2009, p. 151. Tradução minha).

No final da vida, cheio de melancolia pela ausência da mãe e entediado, Barthes entrega-se ao recolhimento, volta ao seu baú sentimental e parte em busca do tempo perdido. O que nos faz rememorar sua obsessão pelos escritos proustianos, sobretudo porque é ali que ele Barthes encontra o estilo de romance que apreciava: anamnésico: “(...) romances que amo (...) [são aqueles] feitos com materiais ('lembranças') evocadas da infância da vida do sujeito. Proust fez disso a teoria de sua obra (...)." (BARTHES, 2005, p. 31).

O surpreendente em Journal de deuil não é a dor do luto pela perda da mãe; disso já sabiam os leitores de Barthes. O que esses escritos trazem de novo é a rendição final do autor e do seu texto à tentação do romance, ou melhor, do romanesco. É com esse o estilo de escritura com o qual Barthes "sonhava alto" (expressão do próprio autor) nas aulas do final dos anos 1970 no Collège de France, em A preparação do romance. Nesse sentido, o romance - não mais nos moldes tradicionais, como uma torrente de fatos, mas como um agrupamento de fragmentos escriturais que testemunham, no sentido religioso - para Barthes, a écriture imortaliza o sujeito de quem fala e o faz vencer a Morte, elevando-o para fora da não memória. Esse Journal de deuil tem uma única figura, a Mãe, que não é a personagem desse diário, mas aquela que justifica a escritura, écriture, e na qual a escritura se justifica.

Ousaríamos, talvez, ler os escritos de Barthes, a partir da década de 1970, quando ele rompe com o método estruturalista e passa a uma fase subjetivista, mais como sintomáticos do que como signo. O romance, como um objeto fantasmático, surge do desejo, da "pulsão" do querer-escrever. Por sua vez, esse querer-escrever nasce de uma fantasia de escritura, do desejo ardente de possuir (imortalizar) o objeto ou o sujeito sobre o qual se escreve, pois escrever, segundo o 
autor, é um verbo intransitivo, na medida em que é preciso haver um objeto/sujeito sobre o qual desenvolve a escritura: um caso de amor, uma fantasia que serve de motor simbólico, um guia para a produção da escritura.

Nesse sentido, as notas do diário armam certa narrativa em torno da dor da perda e da sensação de abandono e de tédio que os dias após o falecimento de sua mãe provocaram na vida do Barthes, maduro, mas sempre muito dependente dela.

Em suma, o que há de mais notável no Diário de luto é que suas páginas nos levam a momentos finais da vida de um dos maiores vultos da intelectualidade francesa, marcadamente umectadas de tédio, melancolia e um cotidiano ínfimo de desespero pela ausência da mãe, somado à incapacidade de tê-la de volta: "ela não está mais aqui, ela não está mais aqui, e nunca mais totalmente." (2009, p. 88. Tradução minha).

\section{REFERÊNCIAS BIBLIOGRÁFICAS}

BARTHES, Roland. A câmara clara: nota sobre fotografia. Tradução de Julio Castañon Guimarães. Rio Janeiro: Nova Fronteira, 2004.

A preparação do romance vol. I. Tradução de Leyla Perrone-Moisés.São Paulo: Martins Fontes, 2005.

A preparação do romance vol. II. Tradução de Leyla Perrone-Moisés.São Paulo: Martins Fontes, 2003.

- Incidentes. Tradução de Mário Laranjeira. São Paulo: Martins Fontes, 2004.

. Journal de deuil. Paris: Seuil, 2009.

O império dos signos. Tradução de Leyla Perrone-Moisés São Paulo: Martins Fontes, 2007.

O neutro. Tradução de Ivone Castilho Benedetti. São Paulo: Martins Fontes, 2003.

LÉGER, Nathalie. Présentation. In: BARTHES, Roland. Journal de Deuil. Paris: Seuil, 2009.

Artigo recebido em: 26/06/2010

Artigo aprovado em: 23/08/2010

Referência eletrônica: FONTANARI, Rodrigo. Roland Barthes. A dor do luto. Revista Criação \& Crítica, São Paulo, n.5, pp. 115-118, Out. 2010. Disponível em:

$<$ http://www.fflch.usp.br/dlm/criacaoecritica/dmdocuments/08CC_N5_RFontanari.pdf> 